\title{
Poesía pintada, poesía por metro. La vanguardia visual en Poémes peintre (1922) de Vicente Huidobro y 5 metros de poemas (1927) de Carlos Oquendo de Amat*
}

Fecha de recepción: 18 de junio de 2019

Fecha de aprobación:octubre 16 de 2019

\section{Resumen}

En el presente artículo se examina la exposición y la construcción de algunos de los Poemas pintados de Vicente Huidobro que exhibió en París, en 1922, hecho que marca, en todo su despliegue de exposición artística, la relación provocadora entre poesía y pintura. De otro lado, se explora la producción de la poesía como objeto estético dinámico y móvil en 5 metros de poemas de Carlos Oquendo de Amat. Con el análisis de esta producción poética se propone establecer una comparación entre los poemas 'Paisaje', de Huidobro, y 'Film del paisaje', de Oquendo de Amat, para señalar cómo la necesidad del diseño y la dimensión gráfico-espacial de los poemas marcaron el espíritu vanguardista en América Latina, al mismo tiempo, esta necesidad llevó, a los dos poetas a concebir la poesía como producción material y estética más allá del soporte y formato tradicional del libro.

Palabras clave: Carlos Oquendo de Amat; poema acéntrico; poema pintado; Vanguardia; Vicente Huidobro.

Citar: Ayram, C. (abril-junio de 2020). Poesía pintada,poesía por metro. La vanguardia visual en Poémes peintre (1922) de Vicente Huidobro y 5 metros de poemas (1927) de Carlos Oquendo de Amat. La Palabra, (37), 57-73. doi https://doi.org/ 10.19053/01218530.n37.2020.9490

\section{Carlos Ayram}

Candidato a Doctor en Literatura de la Pontificia Universidad Católica de Chile. Becario para la Agencia Nacional de Investigación y Desarrollo de Chile (ANID). Magíster en Literatura de la Universidad de los Andes, Bogotá. Licenciado en Lengua Castellana de la Universidad del Tolima. Pontificia Universidad Católica de Chile-ANID cjayram@uc.cl

iDhttps://orcid.org/0000-00026043-0884

* Artículo de reflexión. Este trabajo fue guiado por la Dra. Paula Miranda Herrera durante el seminario: "Poesía Hispanoamericana: modernismos y posmodernismos en la poesía chilena y peruana" en el programa de Doctorado en Literatura de la Pontificia Universidad Católica de Chile. 


\title{
Painted Poetry, Poetry by the Meter. The Visual Vanguard in Poémes Peintre (1922) by Vicente Huidobro and 5 Meters of Poems (1927) by Carlos Oquendo de Amat
}

\begin{abstract}
In this article, examines the exhibition and construction of some of the Painted Poems that Vicente Huidobro exhibited in Paris, in 1922, a fact that marks the provocative relationship between poetry and painting throughout his art exhibition. On the other hand, the production of poetry is explored as a dynamic and mobile aesthetic object in 5 metros de poemas by Carlos Oquendo de Amat. With the analysis of this poetic production I propose to establish a comparison between the poems "Paisaje" by Huidobro, and "Film del paisaje" by Oquendo de Amat, to point out how the need for design and the graphic-spatial dimension of the poems marked the avant-garde spirit in Latin America, while at the same time leading the poets to conceive poetry as a material and aesthetic production beyond the traditional support and format of the book.
\end{abstract}

Keywords: Acentric Poem; Avant Garde; Carlos Oquendo de Amat; Painted Poem; Vicente Huidobro. 


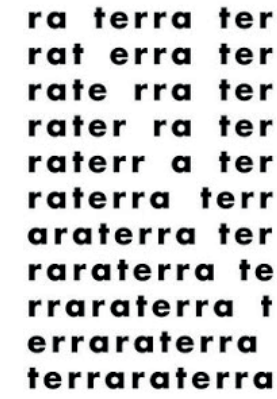

Terra, Décio Pignatari

Sthéphane Mallarmé publicó en 1897, Un golpe de dados jamás abolirá azar, gesto que desmanteló el pacto mimético como promesa para la creación poética. En ese sentido, Mallarmé se atreve a liberar el verso de su prisión métrica, dispone las palabras en tanto la página en blanco lo permite, crea un objeto inaugural del diseño gráfico y considera la escritura como una partitura musical, llena de silencios y sentidos: "añadiré que de este empleo desnudo del pensamiento con repliegues, prolongamientos y fugas -o su dibujo mismo-, resulta una partitura para quien lo lee en voz alta" (Mallarme, 2008, p. 3). La aparición de esta obra, que sigue resistiéndose a una única lectura, permite entrever la singularidad de la actividad poética que marcaría profundamente el espíritu vanguardista de principios y mediados del siglo $\mathrm{XX}^{1}$. No obstante, Un golpe de dados... no solo produjo las condiciones de emergencia de cierta actitud rupturista para la poesía moderna; originó, además, los cimientos de la poesía visual en el que "a la vez de reforzar la visibilidad del grafo otorgándole status matérico, ha creado un locus de resistencia a la linealidad posibilitando una dimensión espacio-temporal múltiple que en sí misma cuestiona el concepto ontológico de pensamiento occidental" (Sarabia, 2007, p. 19).

En este orden de ideas, la aparición de la poesía visual, a fines del siglo XIX, dota de un estatus autorizado a las vanguardias para proponer el viaje del signo por la página en blanco - o negro- y su vinculación con el diseño gráfico y la pintura ${ }^{2}$. Es actitud rupturista frente a la materia verbal hace que la letra impresa cobre vida por fuera del libro como unidad y configura nuevos escenarios de interpretación, lectura y sensibilidad. Así, podría considerarse que la poesía vanguardista, tanto para el caso europeo como latinoamericano - con algunos años se distancia-, instaló la necesidad de desocupar la creación poética del imperativo mimético, lo que produjo una nueva forma de aprovechar el espacio de la escritura como un fenómeno inédito. En ese sentido, estos gestos vanguardistas empiezan a configurar una noción de es-

Indispensable pensar cómo el cubismo y el futurismo son deudores, en cierta medida de Un golpe de dados de Mallarmé. La aparición de la escritura caligramática de Apollinaire, por ejemplo, se emparentan con la búsqueda de cierta dimensión visual sostenida por un cuerpo de signos lingüísticos. Asimismo, el concretismo brasileño, del grupo Noingandres, especificaría que un precursor de la poesía concreta podría hallarse en esta obra que fue considerada por Haroldo de Campos como un poema-constelación: "Liquidando la noción de desenvolvimiento lineal seccionado en un principio-medio-fin en pro de una organización circular de la materia poética" (De campos, 1975, p. 30).

2 Es preciso mencionar aquí los aportes de Apollinaire. El manifiesto cubista (1913) y Caligramas (1918) fueron decisivos para la configuración de una nueva sensibilidad en torno a las artes. Ya que la creación artística deja de ser solo mimética y transforma la realidad a través de la pluridimensionalidad: "El cubismo se diferencia de la antigua pintura porque no es arte de imitación, sino de pensamiento que tiende a elevarse hasta la creación. Al representar la realidad -concebida o la realidad-creada, el pintor puede dar la apariencia de las tres dimensiones, puede, en cierto modo, cubicar" (Apollinaire, s.f., p. 10) 
pacialismo como nueva actitud en torno al uso de la materia verbal, ya no como reflejo de la obligación realista o naturalista, sino como exploración abierta del espacio, por ejemplo, de la página en blanco. Adicionalmente, esta nueva actitud produjo cercanías y relaciones entre las denominadas artes visuales al servicio de la poesía ${ }^{3}$ : pintura, diseño gráfico, ilustración y la video-instalación artística.

En el marco de estas relaciones, me interesa trazar dos casos específicos para las vanguardias peruana y chilena, respectivamente. En primer lugar, quiero preguntarme por la exposición y la construcción de los Poemas pintados que Vicente Huidobro exhibe en París en 1922, hecho que marca, en todo su despliegue de exposición artística, la relación provocadora entre poesía y pintura. En segundo lugar, quisiera articular esa necesidad de emparentar la producción poética con las artes del diseño gráfico en la publicación de 5 metros de poemas de Carlos Oquendo de Amat, que, si bien va señalando cierta vanguardia de corte indigenista, también se interesa en la producción de una poesía como objeto estético dinámico y móvil. Aunque, Oquendo de Amat -presuntamente- no conoció la exposición de Paris en 1922, con seguridad su poemario dialoga con la dimensión espacial y visual lograda por Huidobro en Horizon Carré (1917). Por último, me propongo establecer una comparación entre el poema 'Paisaje' del poeta chileno, que aparece por primera vez en la obra antes mencionada -luego exportada al soporte de la pintura-, y 'Film del paisaje' del poeta peruano. En ambos casos quisiera plantear la necesidad que tienen Huidobro y Oquendo de Amat por el diseño y la dimensión gráfico-espacial de sus poemas, lo que hace pensar en cómo estas actitudes fueron deliberadamente proyectos fundacionales -con sutiles diferencias- que marcaron el espíritu vanguardista en América Latina y llevó, a estos poetas, a concebir la poesía como producción de un objeto material y estético más allá del soporte y formato tradicional del libro.

\section{Poesía y puesta en escena}

En 1922, Huidobro expone una serie de trece poemas en el teatro parisino Edouard VII. La exposición estará pensada por el poeta chileno como una manera de hacer aparecer la poesía en tanto objeto estético, dicho de otro modo, aprovechar la materialidad de la palabra poética en relación con una idea más cercana a la obra plástica, que a la del libro. Rosa Sarabia (2007) advierte, a propósito de este acontecimiento, que la dimensión visual de esta poesía en Huidobro no puede ser entendida a la manera de "Japonerías de estío" o de algunos caligramas de Horizon Carré, sino, se debe comprender "que a la figuración manuscrita se le suman el color y la dimensión cuya enmarcación confiera a esos Poémes peintre calidad de cuadro, y un estatus ontológico de obra de arte" (p. 39). La exposición se abrió el 16 de mayo de 1922, fue clausurada el 18 por "su carácter avanzado"; luego expuesta otra vez en el curso del año, y finalmente cerrada. No será hasta el 2001 que, el Centro de Arte Reina Sofía recuperará los poemas pintados -algunos ya perdidos, otros reconstruidos- y se publicarán en el catálogo Salle XIV. Vicente Huidobro y las artes plásticas (2001).

Habría que considerar antes, de manera breve, la sutil diferencia entre caligrama, poema espacial y poema pintado, ya que Huidobro trabajó obligadamente estas tres expresiones durante su obra poética. La escritura caligramática, que bien podría ser precursora de la poesía visual, apuesta a la construcción de figuras -que representan el contenido del poema- de acuerdo con la disposición tipográfica de las

Habría que considerar como antecedentes, por ejemplo, la hermandad entre poesía y pintura en el Renacimiento y el Barroco -ut pictura poesis-, momento en el que ya se pone a disposición una relación estrecha entre imagen verbal e imagen visual. 
palabras. Esta forma de composición, heredada de Apollinaire y re-apropiada en Huidobro, aparecerá en Canciones en la noche (1913) y Horizon Carré, específicamente, en 'Paisaje', que luego tendrá una transferencia a un distinto soporte material. Por su parte, el poema espacial desarrolla una propuesta gráfica que propone una manera distinta de percibir la realidad a través de la tridimensionalidad ${ }^{4}$, que en Huidobro perfectamente puede estar en Poemas árticos (1918) y en Torre Eiffel (1918), este último hará parte de la exposición en París en calidad de poema pintado. Por último, el poema pintado podría ser la síntesis de las dos primeras formas de composición poética, solo que, en este caso, el texto se imbricará obligadamente con elementos del arte plástico -color, diseño, lienzo- que transfieren el poema del libro al cuadro ${ }^{5}$. Ese desplazamiento de soporte propone otra manera de establecer un pacto de lectura con el texto: el poema será mostrado para ser visto y leído, o sea, a la dimensión lingüística se le suma la cromaticidad y la plasticidad que se vuelve una experiencia de lectura en el espacio de la galería.

La construcción de los poemas hace pensar en cierta dimensión vanguardista que estuvo presente, no solo en la constitución de un espacio para que los poemas-cuadro fueran expuestos ante la mirada, sino que, fueron, a toda costa, expuestos para desafiar los límites de la producción plástica y poética: la poesía renació en el gesto huidobriano como una posibilidad móvil puesta en la escena para la mirada ajena. En este orden de ideas, quiero pensar no solo en la producción final del poema objeto, antes bien, quiero reflexionar si el gesto provocador, naturalmente vanguardista en Huidobro, refleja cierto pensamiento interartístico que obliga a repensar el proceso de producción de la obra ${ }^{6}$. No podría ser posible solo pensar en el acto de presentación de los poemas, más bien, sus condiciones de legibilidad e interpretabilidad están vinculadas con la producción, el diseño, los extravíos, las reconstrucciones. Para ello, quisiera explorar brevemente dos de los trece poemas pintados: 'Moulin' y 'Minuit'? . Quiero concentrarme en estos textos, en primer lugar, porque el primer poema fue inicialmente un caligrama que apareció en el catálogo invitación de 1922 y fue posteriormente reconstruido por la artista Sara Camino Malvar ${ }^{8}$, y el segundo poema, se presenta en todo su despliegue e intención como un poema pintado para la exposición. En segundo lugar, ambos poemas pueden contener la apuesta huidobriana por transportar la poesía a un soporte distinto que crea un pacto estético el marco de una visualidad instalada para la contemplación.

$4 \quad$ Es preciso mencionar que, esa disposición espacial, por ejemplo, en la página en blanco va a ser fundamental por la amistad y relación que tuvo Huidobro con Pierre Reverdy y su tendencia a "sustituir los signos de puntuación y el valor de ritmos y pausas por blancos y espacios" (Goic, 2012, p. 116), así como las diferentes publicaciones llevadas a cabo en la revista Nord-Sud.

5 De acuerdo con Patricio Lizama (2019), los antecedentes de la poesía pintada huidobriana pueden rastrearse en la obra de la pintora francesa Sonia Delaunay. En 1913, esta pintora inicia con colaboraciones sobre los trabajos de Blaise Cendrars, Nicolas Beauduin, Vladimir Maiakovski, Joseph Delteil, Philippe Soupault, entre otros. El trabajo de Delaunay no consistió solo en ilustrar poemas, sino en conferirles una interpretación visual y armonía cromática. Incluso, Delaunay inaugura el género de los poema-cortina en que la poesía es bordada en un textil. De acuerdo con Lizama, "Sonia hace robes-poemes y rideau-poème, estampa y dibuja versos en la ropa y en la tela; Huidobro parte de esta propuesta, pero la modifica, pues hace poemas pintados: los escribe y luego "dibuja/estampa" (p. 107).

6 Estoy pensando, principalmente, en el diseño de la exposición, en los bosquejos y la dimensión archivística de los poemas, sus montajes, sus colaboradores, sus respectivas recreaciones y reconstituciones.

7 Para el desarrollo de este artículo, trabajaré con la edición crítica de Cedomil Goic de las obras completas de Vicente Huidobro. Los poemas analizados e incluidos como figuras están tomados de la sección Salle XIV, cuya introducción y notas críticas pertenecen a Rosa Sarabia.

$8 \quad$ Para Patricio Lizama (2011), Sara Malvar "valora que la poesía huidobriana sea capaz de provocar la suspensión del juicio y transfigurar al lector al desarraigarlo de la realidad empírica y conducirlo a una zona íntima que lo constituye" (p. 50). 


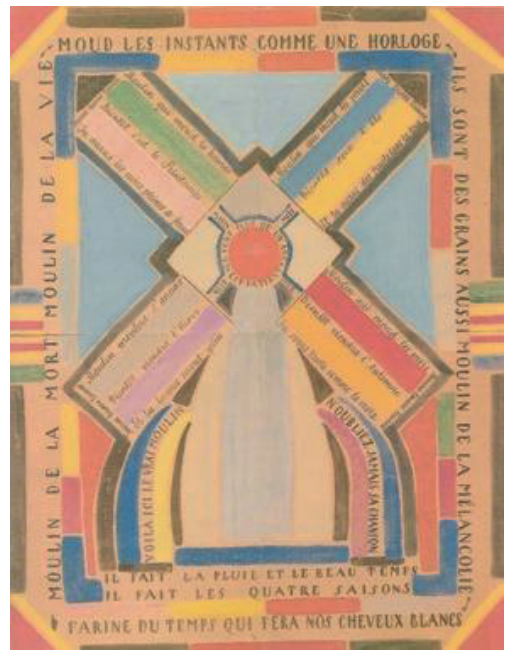

Figura. 1. Moulin, 195. Boceto diseñado por Sara Malvar. (Huidobro 2003a)

'Molino' es un poema que tanto Rosa Sarabia (2007) como Cedomil Goic (2012) han leído como metáfora visual del tiempo. De hecho, la medición del ciclo de la vida está representada en la imagen de un molino, no de un objeto "moderno" como el reloj -si se piensa en 'Teléfono' o 'Aeroplano' de Horizon Carré $^{9}$. La versión original de Moulin, al igual que Paysage, está extraviada; este texto pintado además está intervenido por Camino Malvar ${ }^{10}$.

Sin embargo, en el catálogo, los poemas aparecen en dos versiones distintas: el poema estrófico y su versión visual sin color ${ }^{11}$. Por tanto, hay una decisión que motiva la transferencia del poema estrófico a un cuerpo visual, que construye la imagen del molino. Leo esta decisión de Huidobro, como una liberación del poema hacia el escenario de la exposición artística. El registro visual, completado con el color, se correspondería con la fase final del montaje artístico: es evidente que aquí hay un tránsito de la materia verbal hacia la conquista de cierta plasticidad anclada en la obra de arte.

La constitución de la imagen del molino puede significar un juego con un referente visual instalado culturalmente. La imagen que crea el poema es la imagen de un molino, sin embargo, esa imagen es y será, ante todo, el molino huidobriano, que "muele los instantes como un reloj". La visualidad del poema está marcada no solo por el uso del deliberado del color, sino por el uso de unos rasgos tipográficos -palabras que funcionan como significantes y significados-, conectores -flechas- que le dan un orden al poema. La imagen se mueve de acuerdo con parcelas del tiempo: mañana, medio día, tarde, noche. Las frecuencias temporales se acompañan de las palabras "gira gira gira", en el que la exigencia de una lectura

9 Habría que pensar también que la imagen del molino aparece en el canto $\mathrm{V}$ de Altazor. La palabra 'molino' se reitera constantemente como metáfora del tiempo: "Molino de asiento del viento/ Que teje las noches y las mañanas/ Que hila las nieblas de ultratumba/ Molino de aspavientos y del viento en aspas/ El paisaje se llena de tus locuras" (Huidobro, 2003b. p. 91).

10 No se conoce, hasta el momento, la decisión que llevó a Camino Malvar a pintar el poema con los colores que están dispuestos para ello. El cuadro original se encuentra extraviado.

11 Es importante destacar que 'Molino' tuvo antes de la exposición un tránsito por diferentes medios de publicación. Rosa Sarabia hace un seguimiento de su publicación: en la revista Creación en 1921, luego en el catálogo invitación de 1922, posteriormente como caligrama en el diario Los Tiempos de 1923; y finalmente, reconstruido o pintado en acuarela por Sara Malvar. 
circular haría pensar en cierta dimensión cíclica, probablemente un eterno retorno que puede simbolizar el molino como la imagen del tiempo que pasa y vuelve sobre sí mismo.

'Molino' presenta también una exigencia de lectura particular. La verticalidad conquistada en el poema estrófico se desplaza hacia la presentación del poema como un cuadro. Esa metáfora del tiempo exige que el contrato de lectura sea haga de manera circular, incluso, podría pensarse de manea centrífuga o centrípeta: del centro hacia afuera, de afuera hacia adentro, o solo siguiendo el movimiento de las aspas. La molienda del tiempo "horas, días, meses, años", no es un gesto cronológico, es cíclico. La cosecha, en este caso, no es orgánica, es decir, no se muele el alimento, se muele el tiempo que se ancla en la vida humana y se posiciona como huella indeleble en el cuerpo: "harina del tiempo que hará blancos nuestros cabellos". Los colores introducidos por Camino Malvar le confieren al poema una dimensión más dinámica; su colaboración semiótica apoya y refuerza el contenido lingüístico, incluso, podría hacer que destacara los espacios que están en cada aspa y fijaran la idea de la legitimidad de ese molino, que es "el molino verdadero". El molino no se mueve y produce un efecto de creación absoluta: el molino es el que hace la lluvia, el tiempo y las cuatro estaciones: el poema gesta su propia temporalidad.

Es preciso problematizar aquí el lugar de la poesía, en tanto ejercicio de traducción y desplazamiento de orden semiótico. La producción del objeto artístico, el cuadro expuesto, es un código que ha sido trasladado desde el poema estrófico. Aquí puedo leer un rasgo vanguardista en el que la palabra poética busca un nicho de significación distinta, es decir, el poeta exige y piensa el poema en formas insospechadas para su construcción. ¿Podría acaso pensarse en una dimensión interartística que hace posible la emergencia del poema pintado como objeto de apreciación? ${ }^{12}$ La metáfora del tiempo, que podría ser la matriz dominante del texto poético, se transfiere del caligrama al diseño del cuadro.

Por otra parte, leo 'Minuit' como una apuesta gráfica que trabaja, en este caso, sobre un espacio de color negro. El poema pintado inaugura cierto estilo cósmico en el que la palabra busca generar constelaciones de sentido. La lectura de este poema se resiste a un orden: la génesis de la palabra aparece como urgencia en el espacio negro; el levantamiento de sentido se hace de acuerdo con una palabra que conforma una posible "vía láctea" en el poema. Cabe destacar que, las palabras están sostenidas todas en mayúscula y producen su propia imagen. "La conformidad entre los elementos de universo, consonantes en un mismo espacio tiempo, apuntan a su vez, hacia la preocupación del poeta por el origen, por la creación artística" (Sarabia, 2007, p. 85). El poema es una instalación en un espacio semejante al sideral; las palabras se agrupan como luceros y cuerpos celestes, incluso, como estrellas fugaces, que permanecen en el espacio, lo habitan. El origen de la creación poética se exhibe y se resiste a una lógica única. La palabra llega y se instala, se apodera de un espacio que ya no es símil de la ausencia, sino, de la creación inminente.

"Un astro ha perdido su camino" encuentra un lugar en este poema. El astro se posiciona, se nombra y le da paso a las demás figuras para que se sitúen en ese espacio, que, si bien, es concreto, está delimitado. El astro extraviado, que bien podría funcionar como la poesía misma, crea y asienta cierta dimensión cosmogónica que combate el vaciamiento de sentido, que refulge en el espacio negro. Ya en La creación pura, Huidobro había señalado la relación entre poesía y realidad cósmica en el que la nueva realidad

12 Algo similar sucede, por ejemplo, con el poema 'Torre Eiffel', cuyo texto luego es puesto a disposición del espacio plástico, diseñado según indicaciones espaciales y figurales. 
"debe tener a los astros una atmósfera propia" (Huidobro, 2003c, p. 1313). La disposición de las palabras se adecúa en tanto figuras del espacio sideral: "Nido o átomo" o "he aquí la estrella" configuran la palabra en tanto cuerpo celeste.

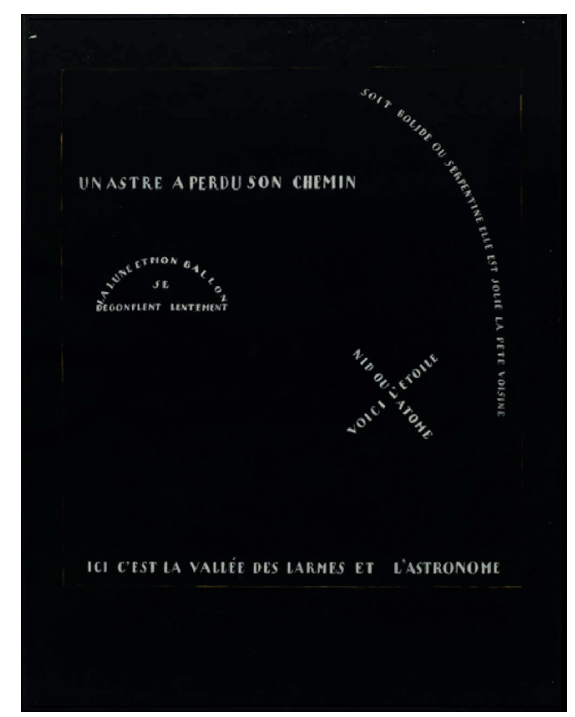

Figura 2. Minuit, 1920-22. (Huidobro 2003a)

Huidobro está estableciendo, en este poema, un pacto con el lector en calidad de espectador. Quiero seguir la idea de Rosa Sarabia (2007) en que afirma que este poema "elabora una poiesis en el que el observador/lector participa del acto creativo" (p. 85). No obstante, añadiría a esta dimensión, también la techné: la poesía en tanto producción material también inaugura un contrato de lectura y apreciación. La recepción de esta cosmogonía poética depende, ciertamente, de la manera en que su diseño se vuelve fundamental como acto comunicativo poético. En 'Minuit' es el espacio negro el que exige el alumbramiento del significante, su recorrido espacial simula un universo, en el que las palabras funcionarán como objetos astronómicos filiados con entidades de sentido. En suma, la exposición de los trece poemas pintados puede gestar la apuesta huidobriana de pactar los diálogos entre el registro poético y el registro plástico. Por ende, la construcción manual y plástica de los poemas otorga solidez a un diálogo entre las artes, específicamente, entre la poesía y la pintura. El despliegue de la exposición concentrará la experiencia poética en una doble vía: primero, hacia la fabricación de un objeto preciso que moviliza el texto poético y lo dispone como obra de arte, es decir, abandona el soporte del libro y se arriesga a generar otra instancia de enunciación; segundo, los cuadros expuestos están al servicio de la mirada: el contrato de lectura operará siempre y cuando las condiciones materiales del objeto expuesto así lo aseguren.

\section{Poesía por metro}

En 1927, en Perú, se publica 5 metros de poemas de Carlos Oquendo de Amat. Si bien la eclosión vanguardista peruana nace con Trilce de César Vallejo, prefigurada ya en Los heraldos negros (1919), es después de 1925 cuando empiezan a aparecer revistas, como Amauta, dirigida por José Carlos Mariátegui con preocupaciones indigenistas, y poemarios como La esperanza i el mar (1927) de Magda Porta- 
les, preocupada por ciertos riesgos experimentales en la producción poética. En ese sentido, Oquendo de Amat también se ocupa de esa dimensión experimentalista en su actividad poética, al tiempo que lidia con las relaciones entre campo y ciudad, que pueden aparecer ya como una constante desde Los heraldos negros de Vallejo: un conflicto entre el espacio comunitario y el espacio modernizado. Al respecto, Cinthya Vich (1998) afirma que:

la actividad poética de Oquendo de Amat (las transformaciones sociales del Perú de los años veinte) se puede llegar fácilmente a la dialéctica entre regionalismo y cosmopolitismo (o entre tradición y modernidad), que constituía uno de los ejes de la discusión intelectual sobre lo "nacional" en la época, y que marcaba algunas de las supuestas diferencias entre los indigenistas y los vanguardistas. (p. 191)

Me gustaría seguir la idea expuesta en la primera sección de este trabajo. Quiero pensar cómo la vanguardia peruana, con 5 metros de poemas, produce un objeto material -y estético- que contribuye a cambiar las condiciones de legibilidad e interpretación de la actividad poética. Al igual que los poemas pintados y expuestos de Huidobro, en calidad de cuadros para ser vistos/leídos, el poemario de Oquendo de Amat es un objeto desplegable, efectivamente, su longitud exacta son casi cinco metros de papel. Si bien hay una diferencia entre el soporte de los Poemas pintados y el formato de los 5 metros de poemas, el poemario de Oquendo no es, en stricto sensu, un libro tradicional, es un objeto de características lúdicas que exige el despliegue de sus rollos, literalmente. En este orden de ideas, el poemario puede ser localizado como un producto inaugural en la vanguardia peruana, incluso, me atrevería a decir, en América Latina. En Oquendo de Amat y Huidobro hay, ya, un coqueteo deliberado con las artes plásticas y visuales que serán aprovechadas a posteriori por los concretistas brasileños. Según Luis Fernando Chueca, Oquendo de Amat:

Desarrolla la exploración más interesante (quizá de todo el idioma), en el campo de lo que hoy se ha dado en llamar "libro-objeto"; esto último no solo por su hoja a modo de los fuelles del acordeón o de "vistas postales impresas en una sola y larga página plegada y encarpetada" 112 -que, desplegada, llega a medir casi los cinco metros que anuncia el título-, o por la composición gráfica de los poemas, sino por la perfecta articulación lograda entre los múltiples sentidos que se desprenden de todos estos elementos con aquello a lo que comúnmente se alude como los "contenidos" del libro. (Chueca, 2009, p. 37-38)

Es preciso advertir la constitución del poemario en tanto objeto estético, incluso, podría atreverme a afirmar que, esa particularidad estetizante está definida si y solo si por el diseño gráfico. El poemario se resiste al formato tradicional de libro, en cambio, propone como gesto vanguardista, que los poemas sean leídos una vez se despliega el papel; la lectura habrá que hacerla en la "medida" de lo posible, en la que la unidad de medición es cada texto que componen estos 5 metros de poemas ${ }^{13}$. Por ejemplo, la primera advertencia del poemario es: "abra el libro como quien pela una fruta" (Oquendo de Amat, 2007 p. 2). Esa advertencia desplaza el sentido del poemario, como un objeto material, a los metros de poema como soporte vital: la analogía logra conciliar dos estados matéricos que guían la experiencia de lectura. De igual modo, el poemario va a establecer el contrato de lectura con su "lector ideal" aquél que pueda sacar y expandir los 5 metros de poemas de su "estuche". La fabricación y diseño del libro reclaman un contacto con su materialidad. Lo mismo sucede con el epígrafe: "estos poemas inseguros como mi primer hablar dedico a mi madre" (p. 2), poemas inseguros, que, como estrategia enunciativa, se proponen

13 De aquí en adelante trabajaré con la edición facsimilar de 5 metros de poemas (2005) de la editorial de la Universidad Ricardo Palma, Lima. Las figuras incluidas en este artículo citarán directamente esta edición. 
inaugurar una ruta de interpretación como si fuera la primera vez que han sido escritos, orquestados en la mente del poeta: acaso un gesto evidentemente vanguardista:

Tuve miedo

Y me regresé de la locura

Tuve miedo de ser

Una rueda

Un color

(Oquendo de Amat, 2005, p. 5)

\section{Un paso}

La dimensión pragmática del lenguaje y la experimentación de la formas lingüísticas y espaciales son rastreables en el poemario de Oquendo de Amat. Según Raúl Bueno (1995) "esa relativa libertad y soltura les permitió [a los vanguardistas hispanos] aliarlo con lenguajes que pertenecen a otras estéticas y corrientes literarias" (p. 40). En este orden de ideas, algunos poemas interfieren el espacio de la escritura poética en busca de una solidaridad expresiva con su lector, acaso un gesto que podría recordar la experimentación con las formas y la disposición del espacio en blanco que Mallarmé comenzó en Un coup de dés jamais n'abolira le hasard (1897). Con todo, el interés de Oquendo de Amat no puede ser solo gráfico. Si el lenguaje es productor de sensibilidades, el poema debería construir un acto de interpelación que ponga al sujeto lírico en una posición exclamativa, interrogativa, interpretativa de su intimidad.

Por ejemplo, el poema ' $\mathrm{j}$ a $\mathrm{r}$ d i n', fechado en 1925, puede ejemplificar tres aspectos. Primero, la apropiación mallarmeana de la página en blanco como potencia de la creación poética, un rasgo claramente espacial que obliga a pensar en el desplazamiento y posicionamiento de las palabras, "los árboles cambian/el color de los vestidos": hay entre estos dos versos una separación espacial que opera como una pausa, que está en contra de la verticalidad.

Segundo, la imagen creadora, que es un rasgo similar en Huidobro, hace que sea, en este caso, la luna la que florezca: "LA LUNA CRECERÁ COMO UNA PLANTA", sostenida toda en mayúscula; una nueva realidad se presiente en un poema que cultiva la palabra y obliga a establecer una realidad a voluntad del poeta. Por último, el juego tipográfico, tan característico del espíritu vanguardista: "u n n i ñ o..." el espaciamiento del verso central, del sujeto que riega aquel jardín, pone en evidencia la distancia entre los significantes que ha producido una sola palabra donde antes podría haber ocho. Esto exige que la lectura sea así misma pactada por esa dimensión tipográfica. La mayor parte de los poemas acuden de distintas maneras a palabras sostenidas en mayúscula. Esa necesidad de insertar estas palabras autoriza al sujeto lírico a interpelar a su lector, redefinir la comunicación poética y

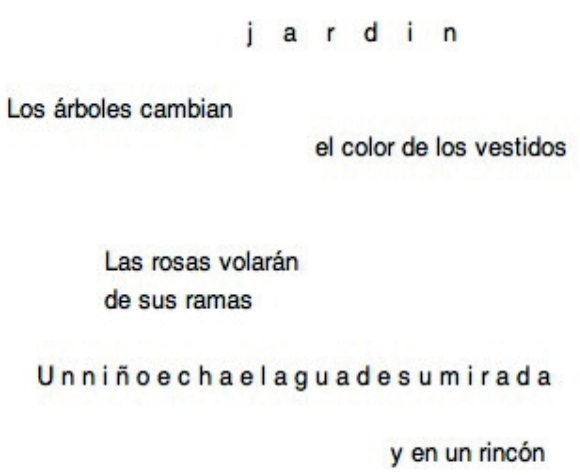

LA LUNA CRECERÁ COMO UNA PLANTA

Figura 3. J a r d i n, Carlos Oquendo de Amat, 2005. 
construir una estancia del poema entre la inminencia del grito y la potencia del silencio, así como en su momento lo hizo Magda Portales con La esperanza i el mar.

\section{Pintar y medir: los paisajes de Huidobro y Oquendo de Amat}

Para terminar, quisiera comparar brevemente dos poemas: 'Paisaje' de Vicente Huidobro y 'Film de los paisajes' de Carlos Oquendo de Amat. Me interesa comparar estos dos textos poéticos no solo por su filiación temática, sino por sus características plásticas y visuales. En el primer caso, el poema de Huidobro se convierte en un cuadro; en el segundo, en Oquendo, hay una intención visual anclada en la visualidad del formato. En todo caso, ambos poemas son perspectivas abiertas sobre la creación poética y el trabajo con procedimientos plásticos y visuales concretos.

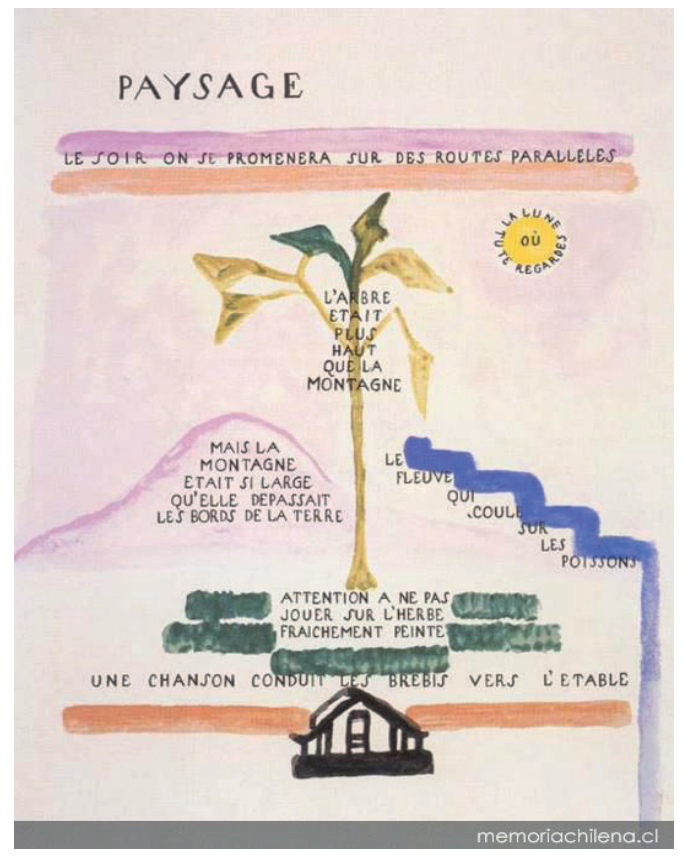

Figura 4. Paysage, 1925. Boceto diseñado por Sara Malvar. Fuente: Huidobro 2003a

Paisaje había ya aparecido en 1917 como caligrama en Horizon Carré. Dedicado a Pablo Picasso, 'Paisaje' es una expresión del creacionismo cubista huidobriano en el que la materia verbal intenta desprenderse de referentes concretos para alumbrar una victoria del poeta en su búsqueda por reconciliar el significante con el significado, gesto definido en El creacionismo: "hacer un poema como la naturaleza hace un árbol" (Huidobro, 2003c, p. 1341). En este orden de ideas, los significantes están agrupados estratégicamente en el poema para producir la imagen de ese paisaje huidobriano. Lizama apunta que: "la mirada describe el espacio real recreándolo y volviéndolo paisaje, de modo que no solo represento un referente previamente existente, sino que también lo produzco" $(2019$, p. 110). No se trata solo de dibujar con las palabras, antes bien, el cuerpo lingüístico entrega las claves de interpretación para su propia instalación cromática. 
Ahora bien, el traslado del poema a la exposición representa un intento por desfamiliarizar la lectura de una realidad operante para remarcarla en una doble vía: de un lado, como poema caligramático que aparece en el catálogo, del otro, como presencia objetual en la sala de exposición. Si bien el poema pintado no es el original, de hecho, es una recreación de la artista Sara Camino Malvar para la exposición del 2001, el poema podría considerarse una puesta en escena en coherencia con la sensibilidad creacionista: "no hay poema si no hay lo inhabitual" (Huidobro, 2003c, p. 1340).

El poema reconstruido por Camino Malvar, respeta la disposición espacial del poema caligramático; en esta versión, se elide la dedicatoria a Picasso y el paisaje simulado aparece delineado con colores, que podría, tal vez, hacer pensar en cierta reduplicación. Podría haber en este sentido, una apuesta de Camino Malvar por adecuar el texto a su apuesta artística; si bien no se conoce el cuadro original, podría advertirse cierta interpretación de parte de la artista sobre cómo fue pintado inicialmente el poema. Leería el gesto de Sara Camino Malvar como un acto de interpretación artística que obliga a pensar en que los poemas son textos claramente abiertos y no obliteran sus posibilidades plásticas. Así, el paisaje constituido no reduplica la imagen lingüística, más bien, pone sobre relieve la condición de cuerpo textual en su dimensión creacionista. En el centro del poema se lee: "El árbol era más grande que la montaña” y la disposición de las palabras son el árbol del poema, que aniquila toda proporción que imagina el árbol, que necesita florecer y la artista al reconstruirlo, propone una imagen arbórea que es el epicentro del poema. El árbol, o mejor, ese árbol, perdió toda referencialidad externa, ahora es el árbol que sostendrá el cuadro.

"Pero la montaña era tan ancha que sobrepasaba los extremos de la tierra" se lee del lado izquierdo del árbol. La montaña crece, en su dimensión figural, hacia la izquierda: el trazo de la montaña se detiene justo en el borde del cuadro: las palabras imaginan la extensión, la imagen la señala, pero el borde no es límite, es confín que se ensancha y sigue su camino. Del lado derecho: "el río que corre sobre sus peces" sufre una ligera variación del poema caligramático: ya no es "el rio que corre no lleva peces". La decisión del cambio obliga entonces a pensar en ese paisaje creado a voluntad del poeta: es la elementariedad la que se subordina a la organicidad del pez, que en este caso es nominal; el río pintado cae y en su caída el color se va aclarando. La caída del agua produce el movimiento en el cuadro: no es un río estático, es un río con una desembocadura.

Llama profundamente la atención la introducción de un elemento, tal vez antipoético, como la advertencia: "Cuidado con jugar sobre el pasto recién pintado". Este aspecto, que podría ser leído en clave de recurso vanguardista - como el uso de mensajes publicitarios-, puede generar cierta actitud absurda en el poema. Sarabia lee este elemento desde la perspectiva del montaje "como un procedimiento técnico y fragmentario particular del cine y la fotografía" (2007, p. 66). De vuelta a Lizama (2019), este indica que:

Malvar enfatiza el encierro del jardín al pintar una reja verde de líneas simétricas y horizontales que lo circunda y lo confirma como un territorio ahogado por las restricciones, las normas académicas y la obligación de imitar la naturaleza nacional: el jardín es una metonimia del encierro existente en el campo literario y plástico chileno. (pp. 112-113)

Pero pienso que también es montaje, no solo por su trabajo con recursos lingüísticos y superposición de imágenes, sino, cómo puesta en escena en el espacio de la circulación artística, en este caso la galería. La 
prohibición no es sobre un objeto es, de nuevo, sobre la materia imaginada: es el pasto recién pintado. Y está recién pintado el color verde rodeando a las palabras: hay una colaboración semiótica entre ambos elementos. El aviso puede renacer en una función poética que también subraya su dimensión artificial. Por consiguiente, la representación de esta naturaleza huidobriana confiere una vida propia a su entorno. El paisaje, entonces, tiene una dimensión cosmogónica: es principio generatriz de una nueva realidad.

Finalmente, el poema abre y cierra con dos versos: uno en la parte superior: "de noche nos pasearemos por rutas paralelas" y "una canción conduce las ovejas al establo". Cedomil Goic, en su estudio Vicente Huidobro. Vida y obra. Las variantes del creacionismo (2012), afirma que hay una relación entre tiempo y sonido en estos versos: un tiempo pensando en futuro que "solo promete el milagro de la hora poética que permitirá el tránsito por rutas paralelas" (p. 121), y el sonido de la canción que conduce al rebaño. En este sentido, es preciso advertir que las rutas paralelas proponen un tránsito del tiempo como entidad simultánea; ese carácter profético anunciado por Goic puede ser en realidad una manera que tiene el propio poema por hacer de la experiencia temporal un evento simultáneo: un tiempo que podría ser entonces un illo tempore, incluso, que podría descansar en la forma en que el poema se escribe, se organiza, se "pinta", incluso, se lee.
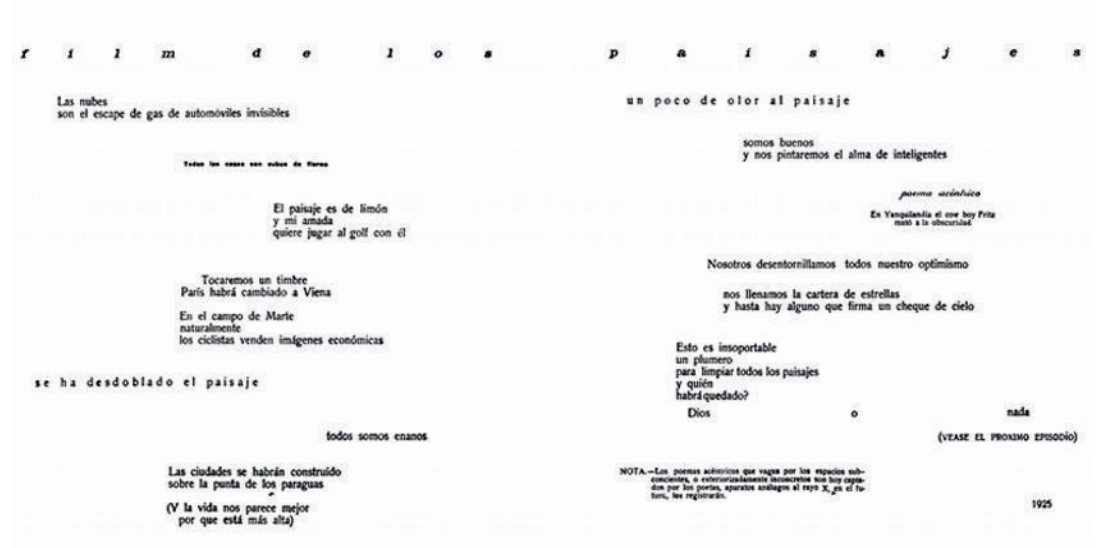

Figura 5. Film de los paisajes.

Fuente: Carlos Oquendo de Amat, 2005.

Por su parte, en 'Film de los paisajes' de Oquendo de Amat, el poeta, en calidad de testigo, ha convocado la imagen en movimiento. El poema resulta de una experiencia modernizante en la que, tal vez, el signo del cine ha cambiado la manera en que una imagen se proyecta y se instala en el mundo. Definitivamente hay un cambio en la percepción y en la sensibilidad poética: se apuesta a una simultaneidad temporal que provocará un orden de la experiencia por entera distinta. El paisaje construido por Oquendo será producto de un proceso de modernización inminente. El poema que se instala en una doble página desestructura una vía canónica de lectura; habrá que leer el poema entre los espacios en blanco, entre los silencios que deposita el hablante con sus juegos tipográficos, su letra menuda, las imágenes cristalizadas de un paisaje sumamente artificial. 
Mas la intención del hablante lírico, que podría identificarse como un sujeto en tránsito desde un espacio rural, no solo consiste en determinar la movilidad de la imagen en tanto reducto de la actividad poética. Aquí, la lectura es hacia el proceso de modernización que devora el espacio urbano, lo transforma de manera inevitable: "las nubes/son el escape de gas de automóviles invisibles" (Oquendo de Amat, 2007, p. 9), se lee como encabezado del poema. El espacio modernizado se presenta en su dimensión artificiosa: el paisaje ha abandonado su lugar como construcción natural, el paisaje ahora se conforma con los residuos de la experiencia industrial, con el cambio arquitectónico: "el paisaje es de limón/y mi amada/ quiere jugar al golf con él" (p. 9). El hablante ha constatado que la emergencia de las ciudades modernas "desdobla el paisaje", cambia las condiciones de vida, implica el nacimiento del espacio por encima de la experiencia comunitaria: "las ciudades se habrán construido/ sobre la punta de los paraguas/ (y la vida nos parece mejor/porque está más alta)” (p. 9).

Entonces, ¿qué sucede con los juegos tipográficos propuestos por Oquendo de Amat y que se funden en su nueva concepción del poema? ¿Cuál es la audacia del poeta cuando hace que el verso se transfigure en un juego de escrituras tipográficas? ¿Qué sucede con la puntuación? Tal vez, ese universo creado por el poeta ha visto la insuficiencia de la puntuación y esta ha sido reemplazada por el vacío de una página en blanco, de un silencio que entra en pugna con la palabra en ese inmenso espacio que la obliga a moverse espacialmente.

El poema de Oquendo le confiere un estatus al lenguaje cinematográfico en tanto posibilidad para la creación poética. No se trata solo del grado de literalidad concentrado por la palabra Film, antes bien, son las imágenes construidas las que entran en una lógica del movimiento. El hablante lírico no se detiene en la ciudad en tanto espacio concreto, percibe la ciudad como una suerte de acumulación de imágenes y nuevos referentes que construyen un sensorium distinto: el hablante siente que "se ha desdoblado el paisaje" (p. 9). Y ese desdoblamiento coincide con la emersión de una sensibilidad distinta en el que "los ciclistas venden imágenes económicas" (p. 9). Ya no hay tiempo para la densidad metafórica, hay tiempo para la imagen que se mueve -tanto en el espacio de la creación como en ese topos imaginario donde se sitúa el hablante-. La urbe cambia las condiciones perceptivas y el lenguaje se ve obligado a ser imagen en movimiento, en ese episodio que propone el sujeto lírico.

Ahora, este texto propone una poética particular: el poema acéntrico. Un poema sin núcleo, nómada, vago, que es captado solo por los poetas como si fueran "aparatos análogos al rayo X" (p. 10). La poesía está en el registro de lo subconsciente: "el poeta, inmerso en lo surreal y con capacidad visionaria, es capaz de concebirlos hoy [poemas] y será apto para representarlos en el porvenir" (Gómez de Tejada, 2018, p. 11). Solo será en esa recolección de los significantes en que se puede establecer un registro de la mirada del hablante, que será puesta hacia el futuro, siempre como proyección. De ahí que, sea el lenguaje fílmico al que acude el hablante el que prometa: "Véase el próximo episodio" (Oquendo de Amat, 2007, p. 10), que podrá continuarse, posiblemente, con el poema 'New York'.

Los paisajes en Huidobro y Oquendo presentan coincidencias en términos formales. Por una parte, encuentro que cada uno construye un paisaje que se desvincula de todo referente naturalizado; los paisajes construidos están creados a voluntad del poeta, de un lado, desde una posición creacionista y, de otro lado, desde la perspectiva del sujeto en tránsito que ha abandonado el espacio rural para adentrarse en el espacio urbano. Ambos poemas están contra la verticalidad del texto poético; ya no hay una intención por convocar el cuerpo estrófico como promesa para la escritura poética, por el contrario, hay una 
vinculación intencionada con el espacio -el lienzo y la página en blanco- que otorgan una dimensión móvil a la escritura y construyen un pacto de lectura distinto: en el caso de Huidobro, un paisaje para ser visto/leído, en calidad de artefacto estético; y en Oquendo, un paisaje para ser leído como imagen en movimiento. Y por el otro lado, los paisajes abiertamente rompen su contrato mimético con la realidad y la naturaleza: no son espejo de aquel mandato que leerá Huidobro en 'Non Serviam': "Yo te responderé que mis cielos y mis árboles son los míos y no los tuyos y que no tienen por qué aparecerse" (Huidobro, 2003d, p. 1294). Asimismo, Oquendo lee esa modernización del paisaje como una suerte de transfiguración en la que este ha cambiado indefectiblemente porque ya no será más la obra de Dios.

Los casos examinados en Huidobro y Oquendo de Amat pueden recordar los planteamientos que Hugo Verani establece en "Estrategias de la vanguardia" (1993). Si bien la preocupación central de Verani es establecer los recursos de enunciación que resultan de la experiencia vanguardista, la producción de poesía-objeto puede ser incluida en el amplio catálogo de la experiencia iconoclasta de vanguardia. Es interesante, no solo explorar Los poemas pintados y 5 metros de poemas como desafíos a "los cánones formales de una tradición petrificada" (Verani, 1993, p. 78), antes bien, producen unas condiciones precisas para que el desafío no sea tanto a la norma escritural sino a sus condiciones de producción, que estarán atadas al proceso editorial, a la dimensión del archivo y al diseño del objeto en tanto "obra" plástica, no solo literaria o poética.

En síntesis, en ambos casos particulares, la poesía se resiste a cierta unicidad, tanto del formato y el soporte como del propio ejercicio de recepción. El poema-cuadro de Huidobro y el poema por metro de Oquendo de Amat son maneras de extremar la actividad poética. Esas relaciones obligadas con las artes del diseño y las artes plásticas convierten a la poesía en la piedra angular de la creación. En su manifiesto "Evolución de las formas: poesía concreta" Haroldo de Campos (1975) asume que

la poesía, como invención de formas, siente las mismas exigencias que las otras artes afines: música y pintura. La melodía en la música, la figura en la pintura, o el discurso-contenidistico-sentimental en la poesía son fósiles gustativos que nada más dicen a la mente creativa contemporánea. (p. 49)

De ahí que, estos gestos vanguardistas puedan convertir la actividad poética en el centro de la experiencia interartística. Tanto Huidobro como Oquendo de Amat establecieron, en su momento, relaciones entre poesía y visualidad que definieron nítidamente una vanguardia visual, como lo que plantearan ambos en sus respectivos paisajes. 


\section{Referencias}

Apollinaire, G. (s.f.). Manifiesto cubista. Recuperado de http://tecnne.com/wp-content/uploads/2013/01/ TECNNE.-MANIFIESTO-CUBISTA.pdf

Bueno, R. (1995). Apuntes sobre el lenguaje de la vanguardia poética hispanoamericana. Hispamérica. Revista de Literatura, (71), 35-48.

Chueca, L. F. (2009). Aproximaciones a la poesía de vanguardia en el Perú. En L. F. Chueca (ed.), Poesía vanguardista peruana, (pp. 9-114). Lima: PUCP Fondo Editorial.

De campos, H. (1975). Evolução de formas poesía concreta. En H. de Campos, D. Pignatari y A. de Campos (eds.), Teoría da poesía concreta. Textos críticos y manifiestos (pp.49-58). Brasil: Livraria Duas Cidades.

Goic, C. (2012). Vicente Huidobro. Vida y obra. Las variantes del creacionismo. Santiago de Chile: LOM Ediciones.

Gómez de Tejada, J. (2018). Carlos Oquendo de Amat: El poema acéntrico como espacio lírico alternativo a la metrópolis moderna. Recuperado dehttps://www.researchgate.net/publication/323877869 El_poema_acentrico_como_espacio_lirico_alternativo_a_la_metropolis_moderna

Huidobro, V. (2003a). Salle XVI y otras ilustraciones. Introducción por Rosa Sarabia. En Obras completas . Madrid: Colección Archivos.

Huidobro, V. (2003b). Altazor. En Obras completas (pp.729-808). Madrid: Colección Archivos.

Huidobro, V. (2003c). La creación pura: En Obras completas (pp.1310-1313). Madrid: Colección Archivos.

Huidobro, V. (2003d). El creacionismo. En Obras completas (pp.1338-1342). Madrid: Colección Archivos.

Huidobro, V. (2003e). Non Serviam. En: Obras completas (pp.1294-1295 ). Madrid: Colección Archivos.

Lizama, P. (2011). Sara Malvar: una intelectual cosmopolita de la vanguardia chilena. Taller de Letras, (48), 47-57. Recuperado de http://letras.uc.cl/LETRAS/html/6_publicaciones/pdf_revistas/ta1ler/t148/04_Lizama_TL48.pdf

Lizama, P. (2019). Sara Malvar: modernidad, manifiesto y poemas pintados. Literatura y Lingüística, (39), 91-118. Doi: http://dx.doi.org/10.29344/0717621x.39.2006

Mallarmé, S. (2008). Un golpe de dados jamás abolirá el azar. Argentina: Babel Editorial. 
Oquendo de Amat, C. (2005). 5 metros de poemas. Lima: Editorial Universitaria de la Universidad Ricardo Palma.

Pignatari, D. (2004). Poesia pois é poesia. 1950 -2000. Cotia, São Paulo: Ateliê Editorial - Editora Unicamp.

Sarabia, R. (2007). La poética visual de Vicente Huidobro. Madrid: Iberoamericana Vervuert.

Verani, H. (1993). Estrategias de la vanguardia. En A. Pizarro (ed.), América Latina: Palavra, Literatura e cultura. Vol 3 (pp. 76-87). Sao Paulo: Memorial.

Vich, C. (1998). Hacia un estudio del indigenismo vanguardista.: la poesía de Alejandro Peralta y Carlos Oquendo de Amat. Revista de Crítica literaria Latinoamericana, 24(47), 187-206

\section{ARTÍCULO RECOMENDADO}

Chico Quintana, R. A. (enero-junio de 2018). La inocencia: configuración semiótica de una propuesta ética en el discurso lírico de Rómulo Bustos Aguirre. La Palabra,(32), 181-200. 